\title{
Cervical facet dislocation adjacent to the fused motion segment
}

\author{
Kunio Yokoyama, Masahiro Kawanishi, Makoto Yamada, Hidekazu Tanaka, Yutaka Ito, Toshihiko Kuroiwa, ${ }^{1,2}$ \\ Department of Neurosurgery, Takeda General Hospital, Fushimi, Kyoto, Departments of ${ }^{1}$ Neurosurgery and ${ }^{2}$ Surgical Pathology, Osaka \\ Medical College, Takatsuki, Osaka, Japan
}

\begin{abstract}
This study reports on a case that forces re-examination of merits and demerits of anterior cervical fusion. A 79-yearold male was brought to the emergency room (ER) of our hospital after he fell and struck the occipital region of his head following excessive alcohol consumption. Four years prior, he had undergone anterior cervical discectomy and fusion of $C_{5} / 6$ and a magnetic resonance imaging (MRI) performed 3 years after this surgery indicated that he was suffering from degeneration of $\mathrm{C} 6 / 7$ intervertebral discs. After arriving at the ER, he presented motor impairment at level $C_{7}$ and lower of manual muscle testing grade 1 as well as moderate loss of physical sensation from the trunk and peripheries of both upper limbs to the peripheries of both lower limbs (Frankel B). Cervical computed tomography (CT) indicated anterior dislocation of $\mathrm{C6} / 7$, and MRI indicated severe spinal cord edema. We performed manipulative reduction of $\mathrm{C} 6 / 7$ with the patient under general anesthesia. Next, we performed laminectomy on $\mathrm{C}_{5}$-T1 and posterior fusion on C6/7. Postoperative CT indicated that cervical alignment had improved, and MRI indicated that the spinal cord edema observed prior to surgery had been mitigated. Three months after surgery, motor function and sensory impairment of the lower limbs had improved, and the patient was ambulatory upon discharge from the hospital (Frankel D). In the present case, although $C_{5}$ and 6 were rigidly fused, degeneration of the $C 6 / 7$ intervertebral disc occurred and stability was compromised. As a result, even slight trauma placed a severe dynamic burden on the facet joint of $\mathrm{C} 6 / 7$, which led to dislocation.
\end{abstract}

Key words: Adjacent segment disease, anterior cervical fusion, cervical facet dislocation, spinal cord injury

\section{Introduction}

Anterior cervical discectomy and fusion is regarded as a gold standard treatment for degenerative cervical spine disease..$^{[1-6]}$ It was reported that this treatment had provided $>90 \%$ likelihood of relief of radicular and myelopathic symptoms. However, anterior cervical fusion has been shown to be associated with the development of new degenerative changes at levels immediately adjacent to the fused segments. ${ }^{[7-10]}$ This study reports on an extremely rare case of a dislocation fracture of segments

\section{Address for correspondence:}

Dr. Kunio Yokoyama, Department of Neurosurgery,

Takeda General Hospital, No. 28-1, Ishidamoriminami-machi,

Fushimi, Kyoto City, Kyoto 601-1495, Japan.

E-mail: neu100@poh.osaka-med.ac.jp

\begin{tabular}{|l|l|}
\hline \multicolumn{2}{|c|}{ Access this article online } \\
\hline Quick Response Code: & Website: \\
\hline & www.ruralneuropractice.com \\
\cline { 2 - 2 } & \\
\hline
\end{tabular}

adjacent to the site of previous anterior cervical fusion caused by slight trauma due to falling.

\section{Case Report}

\section{Presentation and examination}

A 79-year-old male was brought to the emergency room (ER) of our hospital after falling and striking the occipital region of his head following intake of alcoholic beverages. Four years prior, he had undergone anterior cervical discectomy and fusion of C5/6 at our hospital for degenerative cervical spine disease. He suffered no postoperative neurologic symptoms and was independent in his activities of daily living [Figure $1 \mathrm{a}$ and $\mathrm{b}$ ]. At arrival at the ER, he was lucid and found to be suffering from an occipital subcutaneous hematoma. He presented motor

This is an open access article distributed under the terms of the Creative Commons Attribution-NonCommercial-ShareAlike 3.0 License, which allows others to remix, tweak, and build upon the work non-commercially, as long as the author is credited and the new creations are licensed under the identical terms.

For reprints contact: reprints@medknow.com

How to cite this article: Yokoyama $\mathrm{K}$, Kawanishi $\mathrm{M}$, Yamada $\mathrm{M}$, Tanaka $\mathrm{H}$, Ito $\mathrm{Y}$, Kuroiwa $\mathrm{T}$. Cervical facet dislocation adjacent to the fused motion segment. J Neurosci Rural Pract 2016;7:133-7. 

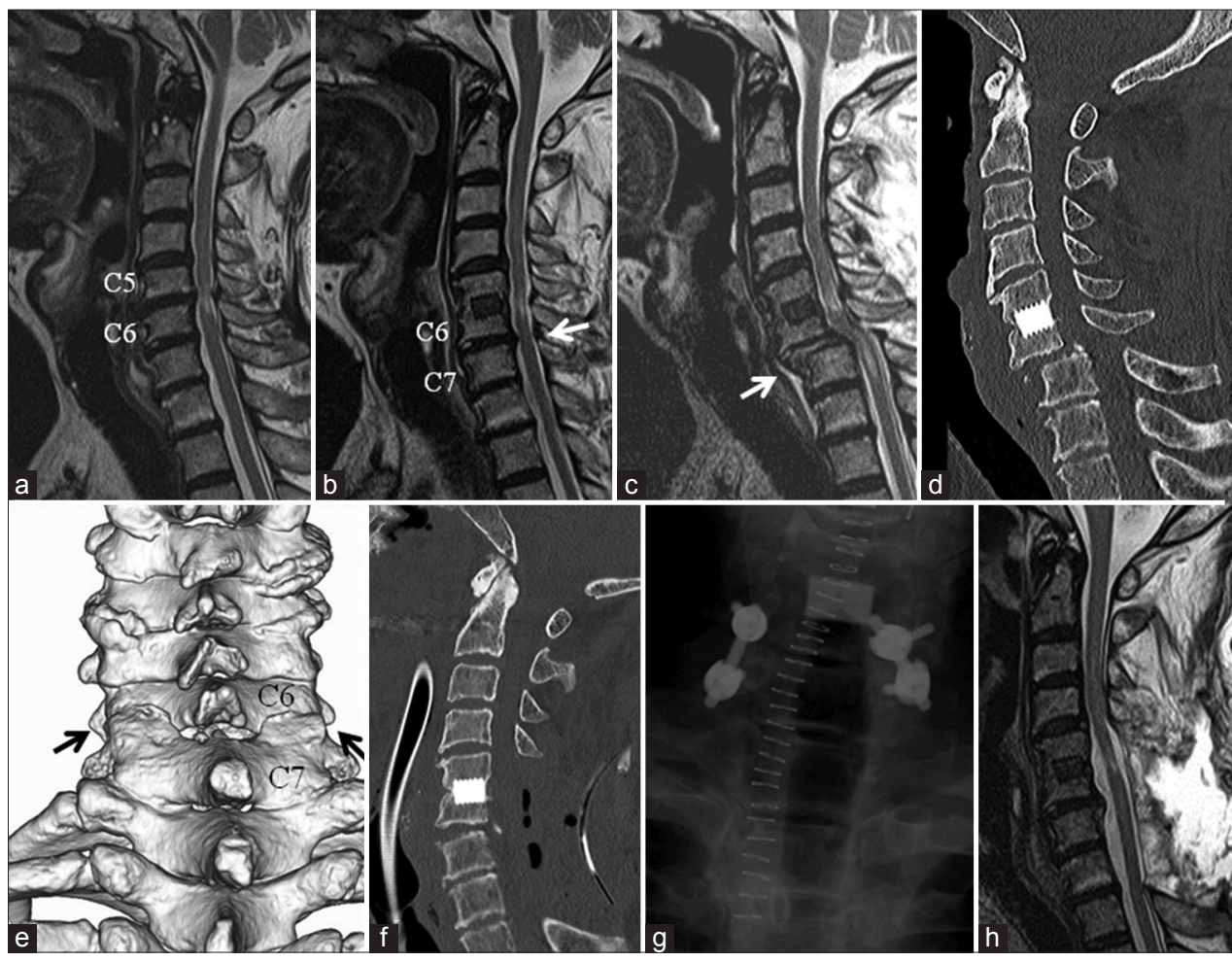

Figure 1: Image findings from before the initial surgery until the completion of treatment. (a) Cervical T2-weighted sagittal images demonstrated the C5/6 intervertebral disc degeneration with local spinal cord edema before the initial surgery. (b) Progress of C6/7 disc degeneration as seen on a T2-weighted sagittal image taken 3 years after C5/6 anterior fusion. (c-e) Anterior facet dislocation (white and black arrows) and severe spinal cord edema identified on magnetic resonance imaging and computed tomography taken after the patient suffered trauma. (f-h) Cervical computed tomography and X-ray after C6/7 posterior fusion indicated improvement in the cervical alignment and magnetic resonance imaging revealed that the spinal cord edema exhibited marked mitigation

impairment at level C7 and below of manual muscle testing grade 1 and moderate loss of sensation from the trunk and peripheries of both upper limbs to the peripheries of both lower limbs (Frankel B). Emergency cervical computed tomography $(\mathrm{CT})$ indicated severe anterior dislocation of C6/7, and magnetic resonance imaging (MRI) revealed severe spinal cord edema [Figure 1c-e].

\section{Surgery and postoperative course}

The patient was brought to the operating room for emergency surgery. Under general anesthesia, the head of the patient was fixed with Mayfield in the supine position. Moreover, under the fluoroscopic guidance, we performed cervical traction slowly and carefully. The manipulative reduction was successfully performed, and the patient was placed in the prone position. We performed laminectomy of C5-T1 and posterior fusion of C6/7 [Figure 1f-h]. For the posterior fusion, we inserted a lateral mass screw into the facet joint of C6 and a pedicle screw into the vertebral body of C7, paying attention to the course of the vertebral artery on both sides [Figure 1g]. Postoperative CT indicated that cervical alignment had improved, and MRI indicated that the spinal cord edema observed prior to surgery had been mitigated [Figure 1h]. There were no problems during the patient's postoperative course, and he actively participated in rehabilitation after being transferred to a rehabilitation hospital. Three months after surgery, motor function and sensory impairment of the lower limbs had improved, and the patient was ambulatory upon discharge from hospital (Frankel D).

\section{Discussion}

Anterior cervical fusion is the established treatment for degenerative cervical disc disease. ${ }^{[1-6]}$ After surgery, intervertebral fusion takes several months while neurological symptoms improve dramatically immediately after surgery. However, it has recently been indicated that one of the long-term postoperative side effects of this surgical treatment is the possibility of degeneration of the adjacent segments. ${ }^{[7-10]}$ Since such cases are said to account for up to $47 \%$ of all patients when asymptomatic cases are included, ${ }^{[9]}$ it cannot be explained simply as the natural course of cervical degenerative disc disease. MRI of the patient, in the present study, indicated clear protrusion of the C6/7 intervertebral disc in comparison to immediately after an initial anterior fusion performed 3 years prior. At 
this point, although there was a possibility that the $\mathrm{C} 6 / 7$ stability was undermined, it was decided to observe the patient's progress as there were no neurological symptoms. However, in a case such as the present patient, in which the anterior dislocation of the segment adjacent to the treated vertebrae was due to slight trauma due to falling rather than high-energy trauma, it is likely that the anterior fusion performed 4 years prior played a major role. Although C5/6 was rigidly fused, the C6/7 intervertebral disc exhibited advancing degeneration and its stability was compromised. This resulted in even slight trauma placing severe dynamic burden on the C6/7 facet, which appeared to lead to the dislocation. Considered in retrospect, it may have been better to have fused C6/7 facet prior to the fall, but this is not normally performed in asymptomatic cases. However, as our search of the medical literature did not reveal any previous reports of anterior dislocation of adjacent segments after anterior cervical fusion, this report is the first on this condition.

The optimal treatment of lower cervical facet dislocation has been controversial. ${ }^{[11-16]}$ Because of the articular process interlocking, intervertebral disc injury, folding and stuck of capsule, anterior and posterior longitudinal ligament, and ligamentum flavum, it is challenging to preserve the spinal cord function during the process of reduction of cervical anatomy. No uniform standards of treatment strategy were available yet, and the surgeon's experience used to be decisive factor, such as closed reduction with skull traction under general or local anesthesia, ${ }^{[3,17]}$ and open reduction and internal fixation (anterior approach; anterior first and posterior second; anterior first and posterior second and then anterior approach; posterior approach; and posterior first and anterior second). ${ }^{[12,18-22]}$ In our case, since MRI performed upon the patient's arrival at the ER indicated severe spinal cord edema, we first performed a laminectomy of C5-T1 after reduction of the dislocation of C6/7. To recover stability of $\mathrm{C} 6 / 7$, we considered an anterior fusion, which is a procedure that we utilize often. However, as we assumed that access would be made difficult by the adhesion accompanying the previous surgery, we opted for posterior fusion in this case. The merit of posterior fusion is that it can be done in a single procedure without changing the patient's position. It should be individualized for every patient; the advantage and disadvantage among so many surgery options should be compared and discussed concisely. ${ }^{[23]}$

\section{Conclusion}

We reported on a case of anterior dislocation of a segment adjacent to a treated vertebra that suffered slight trauma 4 years after an anterior cervical fusion of $C 5 / 6$ was performed. As a result of manipulative reduction, posterior decompression (C5-T1), and posterior fusion (C6/7), the patient's neurological symptoms improved. Anterior cervical fusion is the established treatment for cervical degenerative disc disease, but its merits and demerits require a full reevaluation.

\section{Financial support and sponsorship Nil.}

\section{Conflicts of interest}

There are no conflicts of interest.

\section{References}

1. Awasthi D, Voorhies RM. Anterior cervical vertebrectomy and interbody fusion. Technical note. J Neurosurg 1992;76:159-63.

2. Fraser JF, Härtl R. Anterior approaches to fusion of the cervical spine: A metaanalysis of fusion rates. J Neurosurg Spine 2007;6:298-303.

3. Jacobs W, Willems PC, Kruyt M, van Limbeek J, Anderson PG, Pavlov $\mathrm{P}$, et al. Systematic review of anterior interbody fusion techniques for single- and double-level cervical degenerative disc disease. Spine (Phila Pa 1976) 2011;36:E950-60.

4. Ren C, Song Y, Xue Y, Yang X. Mid- to long-term outcomes after cervical disc arthroplasty compared with anterior discectomy and fusion: A systematic review and meta-analysis of randomized controlled trials. Eur Spine J 2014;23:1115-23.

5. Robinson RA, Smith GW. Anterolateral cervical disc removal and interbody fusion for cervical disc syndrome. Bull Johns Hopkins Hosp 1995;96:223-4.

6. Song KJ, Choi BY. Current concepts of anterior cervical discectomy and fusion: A review of literature. Asian Spine J 2014;8:531-9.

7. Bydon M, Xu R, De la Garza-Ramos R, Macki M, Sciubba DM, Wolinsky JP, et al. Adjacent segment disease after anterior cervical discectomy and fusion: Incidence and clinical outcomes of patients requiring anterior versus posterior repeat cervical fusion. Surg Neurol Int 2014;5 Suppl 3:S74-8.

8. Bydon M, Xu R, Macki M, De la Garza-Ramos R, Sciubba DM, Wolinsky JP, et al. Adjacent segment disease after anterior cervical discectomy and fusion in a large series. Neurosurgery 2014;74:139-46.

9. Carrier CS, Bono CM, Lebl DR. Evidence-based analysis of adjacent segment degeneration and disease after ACDF: a systematic review. Spine J 2013;13:1370-8.

10. Litrico S, Lonjon N, Riouallon G, Cogniet A, Launay O, Beaurain J, et al. Adjacent segment disease after anterior cervical interbody fusion: A multicenter retrospective study of 288 patients with long-term follow-up. Orthop Traumatol Surg Res 2014;100 6 Suppl: S305-9.

11. Cloward RB. Reduction of traumatic dislocation of the cervical spine with locked facets. Technical note. J Neurosurg 1973;38:527-31.

12. Feng G, Hong Y, Li L, Liu H, Pei F, Song Y, et al. Anterior decompression and nonstructural bone grafting and posterior fixation for cervical facet dislocation with traumatic disc herniation. Spine (Phila Pa 1976) 2012;37:2082-8.

13. Hadley M. Treatment of subaxial cervical spinal injuries. Neurosurgery 2002;50:S156-65.

14. Lee JY, Nassr A, Eck JC, Vaccaro AR. Controversies in the treatment of cervical spine dislocations. Spine J 2009;9:418-23.

15. Ordonez BJ, Benzel EC, Naderi S, Weller SJ. Cervical facet dislocation: Techniques for ventral reduction and stabilization. J Neurosurg 2000;92 1 Suppl:18-23.

16. Wolf A, Levi L, Mirvis S, Ragheb J, Huhn S, Rigamonti D, et al. Operative management of bilateral facet dislocation. J Neurosurg 1991;75:883-90.

17. Grant GA, Mirza SK, Chapman JR, Winn HR, Newell DW, Jones DT, et al. Risk of early closed reduction in cervical spine subluxation injuries. J Neurosurg 1999;90 1 Suppl:13-8. 
18. Yu ZS, Yue JJ, Wei F, Liu ZJ, Chen ZQ, Dang GT. Treatment of cervical dislocation with locked facets. Chin Med J (Engl) 2007;120:216-8.

19. Anderson PA, Henley MB, Grady MS, Montesano PX, Winn HR. Posterior cervical arthrodesis with $\mathrm{AO}$ reconstruction plates and bone graft. Spine (Phila Pa 1976) 1991;16 3 Suppl: S72-9.

20. Bartels RH, Donk R. Delayed management of traumatic bilateral cervical facet dislocation: Surgical strategy. Report of three cases. J Neurosurg 2002;97 3 Suppl:362-5.

21. Kim SM, Lim TJ, Paterno J, Park J, Kim DH. A biomechanical comparison of three surgical approaches in bilateral subaxial cervical facet dislocation. J Neurosurg Spine 2004;1:108-15.

22. Payer M. Immediate open anterior reduction and antero-posterior fixation/fusion for bilateral cervical locked facets. Acta Neurochir (Wien) 2005;147:509-13.

23. Ye ZW, Yang SH, Chen BJ, Xiong LM, Xu JZ, He QY. Treatment of traumatic spondylolisthesis of the lower cervical spine with concomitant bilateral facet dislocations: Risk of respiratory deterioration. Clin Neurol Neurosurg 2014;123:96-101. 